AMERICAN JOURNAL OF SCIENTIFIC AND INDUSTRIAL RESEARCH

(C) 2010, Science Huß, http://www.scihub.org/AJSIR

ISSN: 2153-649X doi:10.5251/ajsir.2010.1.3.604.609

\title{
Maximizing the potentials of biogas through upgrading
}

\section{J.I Eze and Agbo K.E}

\author{
E-mail: ikejon85@yahoo.com \\ National Centre for Energy Research and Development University of Nigeria, Nsukka
}

\begin{abstract}
Biogas unlike fossil fuel is a renewable energy source. It is environment friendly fuel and can be generated in every part of the globe where lives exist. Biogas from digester plants contains about $55-65 \%$ methane, $30-45 \%$ carbon (iv) oxide, traces of hydrogen sulphide and fractions of water vapour. Efforts have been made by a number of investigators to improve the quality of biogas by removal of the contaminants through upgrading. This paper reviews various attempts at methane enrichment of biogas, results obtained and the cost implications. There is a lot of potentials in terms of increased energy per unit volume, wobbe index, wider application and ease of handling if biogas is upgraded to $>95 \% \mathrm{CH} 4$. Water scrubbing is cheap and simple. Although upgrading system may be incorporated in a family size plants, it appears that enrichment and compression requirement may only be economically feasible with large plants.
\end{abstract}

Keywords: Biogas, upgrading, wider application, efficient energy use

\section{INTRODUCTION}

Although world energy demand has continued to increase, supplies have dwindled. The present energy systems based on fossil fuel in addition to being finite, damage the natural environment in many and diverse ways, jeopardize human health and exert massive influences upon biogeochemical cycles. These have led credence to the need to turn energy systems towards sustainability.

Biofuel resources are renewable energy and relatively evenly distributed. It is evident that by anaerobic digestion, biogas can be generated from different materials such as animal dung, sewage, industrial effluents, municipal waste, kitchen waste and any matter that once lived. Biogas is a clean, cheap and environment friendly fuel, and has great potentials for wide applications.

Biogas was first used in Bombay in 1859 [IEA, 1997]. Although this technology is known to the Chinese in 1950's and over hundred years old in India [Dioha et al, 2003], it is relatively recent in some developing countries. Biogas utilization in these countries are low despite huge reserves of biogas feedstock. For instance, animal waste and agricultural residues in Nigeria stood at 0.781 million tones per day and 0.256 million tons per day respectively [Sambo, 2007]. This implies that from animal waste alone, Nigeria can generate $4.75 \times 10^{9} \mathrm{MJ}$ per annum. This which is expected to rise [Dioha, 2009], means that a large proportion of that country's energy mix can be sourced from biogas.
At the moment, biogas plants in developing countries do not include upgrading facilities. The implication is that all the $\mathrm{CO}_{2}, \mathrm{H}_{2} \mathrm{~S}$, other contaminants and their combustion products such as $\mathrm{CO}, \mathrm{SO}_{2}, \mathrm{NO}_{\mathrm{x}}$, etc are released to the environment. With the sustained derive towards sustainability in energy systems in the country, the amount of these combustion products will increase and cannot be neglected.

Furthermore, the use of biogas has remained near to the generating plants and compression requirement is high. Special pipes would be required if raw biogas is to be distributed through gas pipelines due to the corrosive nature of $\mathrm{H}_{2} \mathrm{~S}$ content which also impacts unpleasant odour to the raw biogas.

Upgrading raw biogas to $>95 \%$ methane, positions the gas as an alternative vehicle fuel [Navaratnasamy, 2008], and reduces compression and storage requirements [Kapid et al, 2004]. The value added to biogas by upgrading and compression is as good as compressed natural gas; however upgraded biogas has the added advantage of lower emission profile associated with combustion [Nema and Bhuchner, 2002] [Glub and Diaz, 1991].

Raw biogas is mainly used for heating and lighting. Combined heat and power CHP is used to convert biogas from fermentation tanks into electricity. However, in most cases, the heat is not efficiently used as a result of which about $60 \%$ of the energy is lost. Most of the energy loss can be prevented by upgrading to natural gas quality [Mathieu, 2009]. 
Merits of upgraded biogas $\left(>95 \% \mathrm{CH}_{4}\right)$ range from ease of compression, reduced storage requirement to wider applications such as vehicle fuel, efficient generation of electricity, feed stock for chemical industries, fuel cells, etc. From the foregoing it is pertinent to integrate upgrading system in biogas production.

\section{METHODS OF BIOGAS UPGRADING}

A lot of processes are available for upgrading biogas to high methane content. These processes involve the removal of significant amount of $\mathrm{CO}_{2}$ and $\mathrm{H}_{2} \mathrm{~S}$. Most of these processes have been developed for use in the natural gas and petroleum industries. Consequently, some of these methods may not be suitable for process unless high flow rates are involved. Commonly, $\mathrm{CO}_{2}$ removal process also removes $\mathrm{H}_{2} \mathrm{~S}$ [Kapid et al, 2004]. Suitable processes for biogas upgrading include: absorption into liquid (physical / chemical), adsorption on solid surface, membrane separation, cryogenic separation and chemical conversion [Viyaj et al, 2006].

\section{REMOVAL OF $\mathrm{CO}_{2}$}

Absorption into liquid: This method of $\mathrm{CO}_{2}$ scrubbing which may be physical or chemical absorption involves the selective absorption of $\mathrm{CO}_{2}$ from the gas mixture. It is effective and can be used at low gas flow rates [Kapid et al, 2004]. In one form of this method, pressurized water is used as the absorbent. The compressed raw biogas is fed into packed bed column from bottom, while the pressurized water is sprayed from the top in a counter - current process. $\mathrm{CO}_{2}$ and $\mathrm{H}_{2} \mathrm{~S}$ are dissolved in the water and are collected at the bottom of the tower. This method is described as the easiest, cheapest and the simplest method for scrubbing biogas. However, if the water is recycled, the cost increases [Wellinger and Lindberg, 1999].

An upgrading system which employs water as the absorbent and capable of providing $100 \%$ pure methane from biogas has been developed. It was shown that the actual percentage of methane in the upgraded biogas was dependent on factors such as gas pressure, composition of raw biogas, water flow rates, purity of water used and dimensions of the scrubbing tower [Bhattacharya et al, 1988].

In 1989, Khapre [1989] developed a continuous counter - current scrubber operated at gas flow rate of $1.8 \mathrm{~m}^{3} / \mathrm{h}$ at 0.48 bar pressure and water flow rate of $0.465 \mathrm{~m}^{3} / \mathrm{h}$.
Vijay [1989], in search of a more efficient upgrading scrubber introduced a packed bed in the scrubbing system. He used locally available materials which is capable of removing $30 \%$ more $\mathrm{CO}_{2}$ by volume and thus more efficient. A $6 \mathrm{~m}$ high scrubbing tower packed up to $2.5 \mathrm{~m}$ height with spherical plastic balls of $25 \mathrm{~mm}$ diameter was developed at GB pant University of Agriculture and Technology in India. Here, compressed to 5.88 bar pressure, the raw biogas was passed at a flow rate of $2 \mathrm{~m}^{3} / \mathrm{h}$ while water was circulated through the tower. It was found that the set up could remove up to $87.6 \%$ of the $\mathrm{CO}_{2}$ in raw biogas [Shyam, 2002].

Many sewage sludge based biogas plants in America and Europe employ water scrubbing technology for $\mathrm{CO}_{2}$ removal. However with this technology up to $10 \%$ of $\mathrm{CO}_{2}$ remains in the scrubbed biogas [Wellinger and Lindberg, 1999].

A water scrubbing system designed by [Viyaj et al, 2006] reduced $\mathrm{CO}_{2}$ content by $99 \%$. The set up used a gas inlet pressure and flow rate of $1.0 \mathrm{MPa}$ and $1.5 \mathrm{~m}^{3} / \mathrm{h}$, respectively while the corresponding water flow rate was $1.8 \mathrm{~m}^{3} / \mathrm{h}$.

Another form of absorption referred to as chemical absorption involves the formation of reversible chemical bonds between the solute and solvent. The solvent which is not water is regenerated when the bonds formed are broken. The process of bond breaking is endothermic and requires a relatively high energy input. Solvents generally employed include aqueous solutions of amines (mono, di or triethanolamine); or solutions of alkaline salts, polyethylene glycol and their derivatives. For instance Selexol, one of the trade names for solvent, constitutes mainly of dimethylether of polyethylene glycol (DMPEG) [Wellinger and Lindberg, 1999].

According to Biswas et al [1977] 10\% aqueous solution of monoethanol amine (MEA) reduces $\mathrm{CO}_{2}$ content of the biogas by $98 \%$. The used solvent can be regenerated by boiling for 5 minutes and can therefore be used again. The use of alkaline solution $\mathrm{KOH}, \mathrm{NaOH}$ and $\mathrm{Ca}(\mathrm{OH})_{2}$ for the removal of $\mathrm{CO}_{2}$ from biogas was proposed by Savery and Cruzon [1972]. They showed that agitation enhances absorption of $\mathrm{CO}_{2}$ by aiding diffusion of molecules of $\mathrm{CO}_{2}$ in the body of solvents, as well as the concentration of the solvent. Diffusion is most rapid with sodium hydroxide at molarities of $2.5-3.0$ moldm ${ }^{-3}$. Similarly, Eze et al [2007] employed caustic 
soda for the scrubbing of biogas generated from agro wastes.

ADSORPTION: In adsorption processes, the solute $\left(\mathrm{CO}_{2}\right)$ in the raw biogas adsorbs into the surface of a solid material usually by means of weak Van der Waal Forces, London Forces etc. Almost all solids can adsorb, however granular solid with large surface area per unit volume are employed as commercial adsorbents. Good adsorbents are capable of removing $\mathrm{CO}_{2}, \mathrm{H}_{2} \mathrm{~S}$, moisture and other impurities from biogas.

Solid adsorbents used for purification of gas include alumina activated carbon, silica, etc., and are referred to as molecular sieves. Adsorption systems are simple in design and easy to operate. Although they have good moisture holding capacity, the high heat and pressure required make them expensive process [Kapid et al, 2004].

Pressure swing adsorption, PSA is a method used for the separation of $\mathrm{CO}_{2}$ from methane by adsorption I desorption of $\mathrm{CO}_{2}$ on Zeolites or activated carbon at different pressure levels. Adsorbents adsorb $\mathrm{H}_{2} \mathrm{~S}$ irreversibly and are thus poisoned. Consequently, $\mathrm{H}_{2} \mathrm{~S}$ removing step is often included to precede adsorption of $\mathrm{CO}_{2}$ in a PSA process [Jonsson et al, 2002].

Schomaker et al [2002] reported that $\mathrm{CO}_{2}$ could be removed from biogas by pressure swing adsorption which consists of at least three active carbon beds. One of the beds is fed with biogas under pressure (6 bars). $\mathrm{CO}_{2}$ is adsorbed. When there is saturation of $\mathrm{CO}_{2}$ in the adsorption bed, the process is shifted to the second bed. The saturated bed is depressurized to ambient pressure. The efficiency of this process is up to $98 \%$ [Kapid et al, 2004]. This is the method used for a gas upgrading plant in Sweden. In Sweden, continuously monitoring small scaleinstallation of PSA technique in which carbon molecular sieve were used for PSA gas upgrading showed excellent results in terms of clean gas, energy efficiency and cost [Wellinger and Lindberg, 1999].

Natural occurring zeolite (Neopoltion Yellow Tuff, NYT) was used for adsorption by Pandey and Fabian [1989]. They reported that the active adsorption component, chabazite has the adsorption capacity of $0.4 \mathrm{~kg} \mathrm{CO}$ per kg of chabazite at 1.50 bar and $22.8^{\circ} \mathrm{C}$. This method also reduces $\mathrm{H}_{2} \mathrm{~S}$ level.

Membrane separation: The principle of membrane separation is that some components of the raw biogas are transported through a thin membrane while others are retained. Although the permeability is a direct function of the target component in the membrane [Jonsson et al, 2002], the movement of each constituent in the gas mixture is driven by the difference in partial pressure over the membrane [Kapid et al, 2004]. High methane quality requires high permeability of the membrane. Membrane processes are inherently energy efficient, environmentally safe and usually operate at ambient temperature. Due to modular design they can be easily scaled up or operated at reduced capacity [Stein et al, 2000].

Membrane separation technique is of two types: namely high pressure gas separation, and gas liquid adsorption technique. The high pressure separation process which is performed in three stages selectively separates $\mathrm{H}_{2} \mathrm{~S}$ and $\mathrm{CO}_{2}$ from $\mathrm{CH}_{4}$ and gives 96 per cent pure $\mathrm{CH}_{4}$ [Navaratnasamy, 2008]. Gas liquid adsorption is relatively new, operates at low pressure (ca. I bar) and uses micro porous hydrophobic membranes as an interface between gas and liquid. This allows for low cost construction. Under such arrangement $\mathrm{CO}_{2}$ and $\mathrm{H}_{2} \mathrm{~S}$ dissolve while the $\mathrm{CH}_{4}$ portion of the gas is collected [Kapid et al, 2004].

Solid membranes can be constructed as hollow fiber modules to give a large membrane surface per volume and very compact units. Normal operating pressures is in the range of $25-40$ bar. For instance, Hagen and Polman [2001] constructed from acetate cellulose polymer, a solid membrane which has permeability for $\mathrm{CO}_{2}$ and $\mathrm{H}_{2} \mathrm{~S}$ up to 20 and 60 times respectively higher than $\mathrm{CH}_{4}$

A plant was developed for the removal of $\mathrm{CO}_{2}$ from biogas using membrane technique in which it was shown that monsanto and acetate cellulose membrane were more permeable to $\mathrm{CO}_{2}, \mathrm{O}_{2}$ and $\mathrm{H}_{2} \mathrm{~S}$ than $\mathrm{CH}_{4}$ with optimum separation at $25.8^{\circ} \mathrm{C}$ and 5.50 bar pressure [Rautenbach et al, 2001].

Researchers at Syracuse University developed polyimide and poly (ether urethane urea) membranes for removal of $\mathrm{CO}_{2}$ and $\mathrm{H}_{2} \mathrm{~S}$ respectively. The polyimide membrane has much higher $\mathrm{CO}_{2} / \mathrm{CH}_{4}$ selectively and equal or larger permeability to $\mathrm{CO}_{2}$ than cellulose based membrane while the poly (ether urethra urea) has $\mathrm{H}_{2} \mathrm{~S} / \mathrm{CH}_{4}$ selectivity of about 4 times higher than that of cellulose acetate membrane at $35^{\circ} \mathrm{C}$ and 10.14 bars, and permeability to $\mathrm{H}_{2} \mathrm{~S}$ of 93 times higher than that of cellulose acetate membrane under the same conditions [Stein et al, 2000]. 
It is important to note that although the membrane upgrading method can be used to achieve a gas quality of over $98 \% \mathrm{CH}_{4}$, the principles involved in the separation appears to constitute a conflict between high methane purity in the upgraded gas and high methane yield. Increasing the size or number of the membrane modules can improve the purity of the upgraded gas but larger amount of $\mathrm{CH}_{4}$ will be lost [Jonsson et al, 2002].

Cryogenic method of separation: Purification by cryogenic method involves separation of the gas mixture by fractional condensation and distillation at low temperatures. One advantage of this process is the possibility of recovering pure components in the form of liquid. However, complicated flow streams and low thermal efficiency have been reported. Utility requirement and cost are high [Wise, 1981].

In one variation, raw biogas is compressed in multistage to about 80 bar with cooling. In order to avoid freezing during cooling process, the compressed gas is dried. Cooling was achieved by chillers and heat exchangers. The condensed $\mathrm{CO}_{2}$ which is removed in a separator is further processed to recover dissolved methane which is then recycled to the gas inlet, thereby increasing the purity to more than $97 \%$. No data is available on investment and operational cost [Shomaker et al, 2000].

Chemical conversion: This is suitable when high level of purity in the upgraded gas is required. However, it is mostly used after bulk removal of impurities has been achieved by other methods. Methanation is a typical example of chemical conversion. Here $\mathrm{CO}_{2}$ and $\mathrm{H}_{2}$ are converted to methane and water in the presence of catalysts in a highly exothermic reaction [Glub and Diaz, 1991]. Other disadvantages of methanation reaction are the need to remove the generated heat and requirement of large amount of pure hydrogen feedstock. Kapid et al [2004] concluded that the method is generally unsuitable for most biogas upgrading ventures.

Removal of $\mathrm{H}_{2} \mathrm{~S}$ : $\mathrm{H}_{2} \mathrm{~S}$ occurs in biogas at levels ranging from 200 - 5000ppm depending on the feedstock. Although these quantities are relatively small, $\mathrm{H}_{2} \mathrm{~S}$ must be removed. It causes corrosion in compression pumps, gas storage tanks and engines. In addition, the gas is poisonous, environmentally hazardous and gives sulphur (iv) oxide as a combustion product. Removal of $\mathrm{H}_{2} \mathrm{~S}$ from raw biogas may be carried out during upgrading process or in the digester. It is an oxidation process which can be classified into two types depending on the phase in which oxidation occurs. They are oxidation process in the liquid phase and oxidation process in dry condition.

Oxidation in liquid phase may be either physical or chemical absorption process, and is primarily used for biogas that contains low concentration of $\mathrm{H}_{2} \mathrm{~S}$ or previously scrubbed biogas for improved quality. In physical absorption process, $\mathrm{H}_{2} \mathrm{~S}$ is absorbed by solvents such as water, polyethelene glycol, etc. This (delete) [process uses large absorbed by solvents. Such as water, polyethylene glycol etc. this] process uses large amount of water to remove little quality of $\mathrm{H}_{2} \mathrm{~S}$. However if sodium hydroxide is added, absorption of more $\mathrm{H}_{2} \mathrm{~S}$ is enhanced. One of the disadvantages of this is the formation of sodium sulfide or sodium hydrosulfide which is not regenerated and disposal is a problem [Kapid et al, 2004].

Iron (iii) chloride is also used in chemical absorption of $\mathrm{H}_{2} \mathrm{~S}$. In the absorption process, insoluble iron sulphide $\mathrm{FeS}$ is formed. The $\mathrm{FeCl}_{3}$ may be added directly to the digester. This method can reduce the level of $\mathrm{H}_{2} \mathrm{~S}$ to about $10 \mathrm{ppm}$. It is efficient in reducing high level of $\mathrm{H}_{2} \mathrm{~S}$ [Navaratnasamy, 2008], and most suitable for small anaerobic digester system [Kapid et al, 2004].

Dry oxidation method involves the removal of $\mathrm{H}_{2} \mathrm{~S}$ from biogas by conversion to elemental sulphur or oxides of sulphur. This method is preferred with biogas low in $\mathrm{H}_{2} \mathrm{~S}$ content especially when high purities are required for the upgraded gas.

A modified form of this method involves introducing small amount of air / oxygen (usually 2-6\%) in the biogas system through the use of air pump. Oxidation of $\mathrm{H}_{2} \mathrm{~S}$ to sulphur occurs thereby lowering the concentration.

$2 \mathrm{H}_{2} \mathrm{~S}+\mathrm{O}_{2} \longrightarrow 2 \mathrm{~S}+2 \mathrm{H}_{2} \mathrm{O}$

This is simple and relatively cheap. With this method, the concentration of $\mathrm{H}_{2} \mathrm{~S}$ can be reduced to less than 50 ppm. Depending on $\mathrm{CH}_{4}$ content, introducing excess air in the range of $6-12 \%$ may be dangerous because $\mathrm{CH}_{4}$ in air is explosive at the ratio [Wellinger and Lindberg, 1999]. Although this method reduces $\mathrm{H}_{2} \mathrm{~S}$ level, it does not satisfy the $4.6 \mathrm{ppm}$ at $0^{\circ} \mathrm{C}$ recommended pipeline gas quality. In an optimized form by a more sophisticated design, the air is bubbled through the digester feed material [Navaratnasamy, 2008]. 
According to Kapid et al, [2004] $\mathrm{H}_{2} \mathrm{~S}$ may also be removed in an adsorption process where the $\mathrm{H}_{2} \mathrm{~S}$ in the biogas reacts with iron hydroxide or oxides to form iron sulphide. The biogas is passed through iron oxide pellets to remove $\mathrm{H}_{2} \mathrm{~S}$. When the pellets are completely covered with sulphur they are removed and regenerated. Although this method is simple, regeneration is highly exothermic [Navaratnasamy, 2008]. Furthermore the dust packing contains toxic compounds, and the method is sensitive to high water content associated with raw biogas.

Rusty steel wool and wood pellets coated with iron oxides are other forms of iron oxide used. Ferric oxides in the form of iron sponge with wood shavings seem to be the simplest and most economical method involving the use of iron oxide. For instance, iron sponge of $0.035 \mathrm{~m}^{3}$ will remove $3.7 \mathrm{~kg}$ of sulphur [Norris, 1943] at inlet conditions of 0.2 percent $\mathrm{H}_{2} \mathrm{~S}$, this volume of iron sponge will remove the $\mathrm{H}_{2} \mathrm{~S}$ from approximately $2,500 \mathrm{~m}^{3}$ of gas. Regeneration involves exposing the iron sponge to air (oxygen) which converts the ferric sulphide formed by the scrubbing operation back to ferric oxide and elemental sulphur [Dioha et al, 2003]. Furthermore, $100 \mathrm{~g}$ of wood chips coated with iron oxide can bond as much as $20 \mathrm{~g}$ of $\mathrm{H}_{2} \mathrm{~S}$. It has the advantage of low cost; however care must be taken to avoid too high temperature during regeneration.

Activated carbon can also be used to adsorb $\mathrm{H}_{2} \mathrm{~S}$ from biogas. In a more efficient form, the activated carbon is impregnated with potassium iodide. This catalytically reacts with oxygen and $\mathrm{H}_{2} \mathrm{~S}$ to form water and sulphur, and is best carried out at 7 to 8 bar and 50 to $70^{\circ} \mathrm{c}$. The system requires regeneration or outright replacement when saturated [Navaratnasamy, 2008].

Economics of upgrading plants: A study on 11 Swedish biogas upgrading systems shows that the cost of upgrading depends very much on the plant size. While small plants for $<100 \mathrm{~m}^{3} / \mathrm{h}$ raw gas have upgrading costs of between 3 and $4 € c t / \mathrm{KWh}_{\text {upgraded }}$ gas, that of upgrading plants in the range of 200$300 \mathrm{~m}^{3} / \mathrm{h}_{\text {raw gas }}$ cost around $1-1.5 € \mathrm{ct} / \mathrm{KWh}_{\text {upgraded gas }}$. Furthermore, the energy demand for the upgrading process was only 3-6\% of energy content in the upgraded gas [Jonsson and Persson, 2003].

Estimation by a model developed in Pakistan for purification, compression and bottling of biogas in cylinders for decentralized distribution showed that the whole process requires a $25 \%$ of the energy generated per day [llyas, 2006].

It therefore means that upgrading of raw biogas to high methane content is a worthwhile venture.

\section{CONCLUSION}

In order to achieve high methane levels in the upgraded gas, and in a manner that is environment friendly and cost effective, scrubbing methods capable of simultaneous removal of the contaminants and least methane losses are naturally favored. Water scrubbing is simple, cost effective and a practical method of upgrading even in rural setting and therefore remains the best option.

Efficient use of energy resources is an important aspect of energy management. More so where meeting energy demand by supply has remained elusive. Upgrading raw biogas to high methane content is one form in which biogas energy resource can be efficiently used, and in a sustainable manner.

\section{REFERENCES}

Bhattacharya T K, Mishra T N, Singh B (1988) Techniques for removal of $\mathrm{CO}$ and $\mathrm{HS}$ from Biogas. Paper presented at XXIV annual convention of ISAE, held at PKV, Akola.

Biswas T D, Kartha A R S, Pundarikakhadu R. (1977) Removal of carbon dioxide from biogas: Proceedings of national symposium on biogas technology and uses. New Dehli, IARI .

Dioha I. J, Baba I.M. and Sambo A.S. (2003) Potentials of Natural Gas Energy in Nigeria Energy Mix. Nigerian Journal of Solar Energy, vol 14, pp 1-5

Dioha J I, (2009) Overview of Biomass Resources of Nigeria: A Presentation at a 3-day national training workshop on biofuels for sustainable energy development I Nigeria, 22-24 June 2009, NARICT, Zaria

Eze J I, Onwuka N D and lloeje O C (2007) Generation of Biogas from Agro wastes. Nigerian Journal of Solar Energy. Vol 18 pp 157-165.

Glub J.C and Diaz L.F.(1991) Biogas purification process. Biogas and alcohol fuels production. vol 2. J P Press Inc.

Hagen M. and Polman E. (2001) Adding gas from biomass to gas grid. Final report submitted yo Danish gas Agency; 2001:26-47 
IEA Bioenergy Task. http://www.sgc.se/biogasfaq/ accessed on 21052009

Ilyas S. Z. (2006) A Case Study to Bottle the Biogas in Cylinders as Source of Power for Rural Industries Development in Pakistan.World Applied Sciences Journal 1 (2): 127-130

Jonsson O, Erik P, Jan K J., Rolf E, Hakan S, and Staffan I (2002) Sustainable Gas enters the European gas distribution system. http://www.dgc.dk/publikationer/konference/jkj su stain gas.pdf .accessed on 21052009

Jonsson O. and Persson M. (2003) Biogas as transportation fuel Fachtagung 2003 available at http://www.fvee.de/fileadmin/publikationen/works hopbaende/ws2003z/ws2003 202 04.pdf.accessed on 28082009.

Kapid S.S., Viyaj V.K., Rajesh S.K., Prasad R., (2004) Biogas Scrubbing, Compression and Storage: perspective and prospectus in Indian context.

http://www.sciencedirect.com/science? ob=Articl e URL\& Udi. accessed on 28042009.

Khapre U L, (1989) Studies on biogas utilization for domestic cooking; Paper presented at XXV annual convention of ISAE, held CTAE, Udaipur.

Mathieu M.H.M , Upgrading to Natural gas quality From biogas to green gas.Platform Nieuw Gas. http://www.senternoven.nl/mmfiles/Brochure\%20 From\%20Biogas\%20to\%20Green\%20\%20Upgrading\%20to\%20natural\%20gas\%20qua lity-tcn24-233016.pdf. Accessed on 02092009

Navaratnasamy M. (2008) Biogas: Cleaning and Uses. Agrifacts Agdex 768-5 June., 2008.Avaliable at http://wwwl.agric.gov.ab/\$department/deptdoc.nsf /all/agdex768-5. accessed on 12072007

Nema A and Bhuchner K. (2002) Kampogas- a robust technology for solid waste to energy projects. Bio-Energy News 6 (2) 10-12

Norris A. (1943) Scrubbing Sewage Gas. Water and Sewage works 90:61

Pandey D R and Fabian C (1989) Feasibility studies on use of naturally occurring molecular sieves for methane enrichment from biogas. Gas separation and purification 3:143-147
Rautenbach R. Ethresmann E. and Wayer H. (2001) Removal of carbon dioxide from fermentation gas by membrane separation. Chem Abstract 1987107 (14:154)

Sambo A.S (2007) Renewable Energy Development in Nigeria: A situation Report; A keynote address presented at the International Workshop on Renewable Energy for Sustainable Development in Africa, IWRESDA , $30^{\text {th }}$ July to $1^{\text {st }}$ August,2007

Savery W C and Cruzon D C (1972) Methane recovery from chicken manure. J. Water Pollut Control Fed 1972; 44:2349-2354

Shomaker T I, Boerboom AHHM, Vissel A and Pfeifer A E (2000) Technical summary on as treatment. Anaerobic digestion of agro wastes: information network project FAIR-CT96-2083

Shyam M (2002) Promising renewable energy technologies.AICRP technical bulletin number CIAE/2002/88; 2002:47-48

Stein S. A Rice P.A and Hao J. (2000) Comprehensive Technical report on upgrading Natural Gas via Membrane Separation processes.DE-FG 21-91MC 28072 Federal Energy Technology Center, US Dept of Energy; Morgantown. WV 2000.

Vijay V K, (1989) Studies on utilization of biogas for improved performance of dual fuel engine. $M E$ (Ag) thesis. CTAE, Udaipur.

Viyaj KV, Chandra R, Subbarao P M V and Kapid S $S$ (2006) Biogas purification and Bottling into CNG Cylinders: Producing Bio-CNG from Biomass for Rural Automotive Applications. A paper presentation at The $2^{\text {nd }}$ Joint International Conference on Sustainable Energy and Environmetnt (SEE) on 21-23 November 2006 Bangkok, Thailand.

Wellinger A and Lindberg A (1999) Biogas upgrading and utilisation.IEA Bioenergy Task 24: Energy from Biological conversion of organic waste.1999,3-19

http://www.biogasmax.eu/media/biogas upgradin $\mathrm{g}$ and utilisation 018031200101124042007. pdf Accessed on 2142009

Wise D L (1981) Analysis of systems for purification of fuel gas. Fuel gas production from biomass. vol 2. Boca Raton, FL:CRC Press 1981. 